\title{
Effects of Duties in Terminal Patients Wards on Nurses Well-Being
}

\author{
Waqas Siddique \\ M.Phil. Sociology, Lahore Leads University, Lahore (Pakistan) \\ Naseem Sarfraz \\ M.Phil. Sociology, Lahore Leads University, Lahore (Pakistan)
}

Working as Medical Social Officer (MSO), Shalamar Medical and Dental College, Lahore (Pakistan)

Dr. Noor-ul-ain Daud

MBBS, Demonstrator at Shalamar Medical and Dental College, Lahore (Pakistan)

Dr. Ahmed Saud

MBBS, M.Phil Public Health, Demonstrator at Shalamar Medical \& Dental College, Lahore (Pakistan)

Dr. Farkhanda Siddique

Assistant Professor, Lahore Leads University, Lahore (Pakistan)

\begin{abstract}
OBJECTIVES: This study was undertaken to explore the working conditions of nurses and well-being during performing their duties in terminally ill patients' wards in B.V.H and find out the problems faced by them and to assess the impact of these problems on the social lives on nurses of Bahawal Victoria Hospital. METHODS: Survey method was used to collect data from respondents. A total of 214 nurses are working in terminally ill patients wards B.V.H from them sample size of $50 \%$ was selected randomly from all the wards of B.V.H with the response rate of $87 \%$. Data was collected from 109 respondents using a self-administered questionnaire as a tool of data collection.RESULTS: The biggest problem faced by nurses in B.V.H is of excessive work load; nurses have to work a lot, B.V.H is facing grave scarcity of nursing staff. Due to intense nature of job, majority of nurses are victim of job stress. Job stressed has also proved to be cause of physical and psychological illnesses; like insomnia, dementia, hypertension and other disorders. What add to the injury is that apart from performing clinical duties, nurses also have to perform ward management as well. They have to maintain the records of medicine inventory in ward, maintain indent book and they are also responsible for the security of machinery or any equipment's present in the ward. Most of the nurses are annoyed from patient's attendants and consider them as the biggest hindrance in their job performance.CONCLUSION: Government must provide the accommodation facilities like staff colony for the nurses. The hospital administration should reduce the working hours of nurses to make some sort of relive Born their workload' There must be sufficient paid leaves in a year for the nurses. A proper service structure should be developed so the promotions and demotions should be done in accordance with some Preset rules and standards. The health department must also provide pick and drop services to the local nursing staff. Male nurses should be appointed especially for the night shift. Quick and strict action should be taken against those who try to harass the nursing staff.
\end{abstract}

Keywords: Nurses, Terminal Patients Wards, Hypertension, Insomnia, Dementia, Harassment.

DOI: $10.7176 / \mathrm{JHMN} / 80-07$

Publication date:September $30^{\text {th }} 2020$

\section{Introduction}

Nurses play an integral part in ensuring quality health care. According to Diers (2004) "Nursing is the care of the sick and those who may become sick, and the maintenance of the environment in which care occurs. Nurses are also responsible for fulfilling certain aspects of the medical regimen delegated to them by physicians, such as administering medication. They have a legal and moral obligation to deliver age-appropriate medication to each patient using the proper route of administration (i.e. intravenous, and oral)".

In Pakistani society, where conventions still rule and there are social taboos identifying with female activities, ladies have more commitments predominantly as housewives. No general public in this world is free from social issues since life isn't fixed yet progress, constant and now and again confounding. Working ladies face various difficulties because of their new methods of life. Ladies are as yet being segregated lined up within the work environment around the world, with Pakistan having probably the most minimal rate on the planet for female commitment in the workforce and there is an immense hole in sex in the business zone.

Health care system of any country is regarded as an indicator of social development of that country. Nurses are an integral part of the health care system of Pakistan. Nurses"e plays a vital role in providing health care 
services in Pakistan. In all the Abrahamic religions, nursing profession is given respect and is recognized as an act of philanthropy. Shortage of nursing staff and intense loads of work has been a story in all the nursing history of Pakistan. Nursing profession and nurses in particular had never been given due respect and prestige what it deserves.

\section{Literature Review}

According to American Nurses Association (ANA) "Nursing is the protection, promotion, and optimization of health and abilities, prevention of illness and injury, alleviation of suffering through the diagnosis and treatment of human response, and advocacy in the care of individuals, families, communities and populations".

Studying nursing history helps one better appreciate the social dynamics and the problems that the profession continues to face. Understanding the history of nursing also enables us to appreciate the role that nursing profession has played in the world's health system (Donahue, 1991).

Because no formal education was available in the care of the sick, earliest nurses learned this art through oral traditions that passed from generations to generations, from observations of others caring for the sick, and many times through trial and error processes (Nutting \& Dock, 1907).

\section{Methodology}

\section{A. Research Design:}

A social inquiry requires a concept or a process before data collection or research can begin. A research design is not a mere plan of work. A task plan outlines what has to be accomplished in order to finish the project but the work plan must flow from the conceptual phase of the project.

\section{B. Quantitative Study:}

This study was quantitative in nature. Survey method is used to conduct this study, because we needed surface information so questionnaire is used as a tool for data collection and due to high population of nurses ${ }^{\text {ee }}$ survey method is appropriate for this study.

\section{Sampling:}

There are 214 nurses working in Bahawal Victoria Hospital in terminally ill patients' wards such as emergency, ICU, cardiology, surgical, HIV and kidney ward. Respondents were selected randomly from all these wards from morning, evening and night shifts.

\section{Sample Size:}

105 nurses selected randomly as sample size.

\section{E. Validity:}

Legitimacy alludes to the degree to that partner degree instrument estimates what it's affirmed to gauge'. As such, a legitimate instrument really measures the idea it is speculative to quantify Polit and Hungler 1989; De Vos et al 2005). (As per Polit and Beck; 2004 and De Vos et al 2005), three principal approaches for surveying the legitimacy of instruments all around idea out to gather quantitative information are content legitimacy, rule related legitimacy and build legitimacy. In this investigation, develop and content legitimacy was utilized to survey the legitimacy of the instruments by methods for evaluating the sufficiency, reasonableness, breadth, and significance of the inquiries to the subject under examination was surveyed.

\section{F. Reliability:}

As indicated by PolitandBeck (2004), dependability is the consistency with which the instrument estimates the objective point. This implies regulating a similar instrument by different scientists will give similar outcomes under on a par with conditions (De Vos et al 2005). Unwavering quality of a device can be compared to clearness, quality, soundness, consistency, sufficiency, and precision of the estimating instrument (Polit and Hungler 1989; Varkevisser et al 1991:152).

\section{G. Development of Data Collection Tool:}

Self-administered questionnaire was designed as a tool for data collection, keeping in mind that all the respondents are well educated, at least metric and diploma in nursing. Questionnaire was developed after detailed discussion with the senior nurses of B.V.H and in accordance with the objectives of the study. Before developing the questionnaire two detailed discussion sessions were conducted with Dy. Superintendent of Nursing.

\section{Results and Discussion:}

The data analysis comprises on the contingency tables downgrading the categories, frequency and percentages of the variables. Moreover, the Chi-Square test is applied to check impacts and associations between the variables. 
Table 1: Age

\begin{tabular}{|l|r|l|l|}
\hline Age & Frequency & Percentage & Valid Percentage \\
\hline $20-25$ & 50 & 47 & 47 \\
\hline $26-30$ & 20 & 19 & 19 \\
\hline $31-36$ & 20 & 19 & 19 \\
\hline Above 37 & 15 & 15 & 15 \\
\hline Total & 105 & 100 & 100 \\
\hline \multicolumn{4}{|c|}{ Mean $=1.36 \quad$ S.D $=.607$} \\
\hline
\end{tabular}

Table 2: Marital Status

\begin{tabular}{|l|l|l|l|}
\hline Response & Frequency & Percentage & Valid Percentage \\
\hline Married & 50 & 47.7 & 47.7 \\
\hline Unmarried & 20 & 19.05 & 19.05 \\
\hline Divorced & 15 & 14.25 & 14.25 \\
\hline Widow & 20 & 19 & 19 \\
\hline Total & 105 & 100 & 100 \\
\hline
\end{tabular}

Mean $=1.71 \quad$ S.D $=.927$

Table 3: Qualification:

\begin{tabular}{|l|l|l|}
\hline Response & Frequency & Percentage \\
\hline Graduation & 74 & 70.48 \\
\hline master & 28 & 26.66 \\
\hline M.Phil & 3 & 2.85 \\
\hline PhD & 0 & 0 \\
\hline Total & 105 & 100 \\
\hline \multicolumn{2}{|c|}{ S.D $=.709$}
\end{tabular}

Table 4: Do you feel stress at you work place?

\begin{tabular}{|c|c|c|c|c|}
\hline Responses & Frequency & Percent & Valid percent & Cumulative percent \\
\hline Yes & 88 & 84.0 & 84.0 & 84.0 \\
\hline No & 17 & 16.0 & 16.0 & 100.0 \\
\hline Total & 105 & 100.0 & 100.0 & \\
\hline
\end{tabular}
Mean $=2.65$
$\mathrm{S} . \mathrm{D}=1.662$

Table 5: Feelings about the nature of your job tasks.

\begin{tabular}{|l|c|c|c|c|}
\hline Responses & Frequency & Percent & Valid percent & Cumulative percent \\
\hline Slightly intensive & 23 & 21.9 & 21.9 & 21.9 \\
\hline $\begin{array}{l}\text { Moderately } \\
\text { intensive }\end{array}$ & 34 & 32.4 & 32.4 & 54.3 \\
\hline Highly intensive & 48 & 45.7 & 45.7 & 100.0 \\
\hline Total & 105 & 100.0 & 100.0 & \\
\hline
\end{tabular}

Table 6: Are working conditions healthy?

\begin{tabular}{|c|c|c|c|c|}
\hline Responses & Frequency & Percent & Valid percent & Cumulative Percent \\
\hline Strongly Agree & 15 & 14.2 & 14.2 & 14.2 \\
\hline Agree & 10 & 9.6 & 9.6 & 23.8 \\
\hline Not Sure & 5 & 4.8 & 4.8 & 28.6 \\
\hline Disagree & 36 & 34.2 & 34.2 & 62.8 \\
\hline Strongly Disagree & 39 & 37.2 & 37.2 & 100.0 \\
\hline Total & 105 & 100.0 & 100.0 & \\
\hline
\end{tabular}


Table 7: Do you feel that physical dangers exist at your work place?

\begin{tabular}{|c|c|c|c|c|}
\hline Responses & Frequency & Percent & Valid percent & Cumulative Percent \\
\hline Strongly Agree & 39 & 37.2 & 37.2 & 37.2 \\
\hline Agree & 36 & 34.2 & 34.2 & 71.4 \\
\hline Not Sure & 5 & 4.8 & 4.8 & 76.2 \\
\hline Disagree & 10 & 9.6 & 9.6 & 85.8 \\
\hline Strongly Disagree & 15 & 14.2 & 14.2 & 100.0 \\
\hline Total & 105 & 100.0 & 100.0 & \\
\hline
\end{tabular}

Table 8: Do you have to perform heavy physical tasks?

\begin{tabular}{|c|c|c|c|c|}
\hline Responses & Frequency & Percent & Valid percent & Cumulative percent \\
\hline Strongly Agree & 39 & 37.2 & 37.2 & 37.2 \\
\hline Agree & 36 & 34.2 & 34.2 & 71.4 \\
\hline Not Sure & 5 & 4.8 & 4.8 & 76.2 \\
\hline Disagree & 10 & 9.6 & 9.6 & 85.8 \\
\hline Strongly Disagree & 15 & 14.2 & 14.2 & 100.0 \\
\hline Total & 105 & 100.0 & 100.0 & \\
\hline
\end{tabular}

Table 9: Promotions are made justified?

\begin{tabular}{|l|c|c|c|c|}
\hline Responses & Frequency & Percent & Valid percent & Cumulative Percent \\
\hline Strongly Agree & 24 & 22.8 & 22.8 & 22.8 \\
\hline Agree & 28 & 26.7 & 26.7 & 49.5 \\
\hline Not Sure & 20 & 19.1 & 19.1 & 68.6 \\
\hline Disagree & 22 & 20.9 & 20.9 & 89.5 \\
\hline Strongly Disagree & 11 & 10.5 & 10.5 & 100.0 \\
\hline \multicolumn{1}{|c|}{ Total } & 105 & 100.0 & 100.0 & \\
\hline
\end{tabular}

Mean $=2.88$

S.D $=2.134$

Table 10: Job security?

\begin{tabular}{|c|c|c|c|c|}
\hline Responses & Frequency & Percent & Valid Percent & Cumulative Percent \\
\hline Very secure & 19 & 18.1 & 18.1 & 18.1 \\
\hline Secure & 20 & 19.1 & 19.1 & 37.2 \\
\hline Unsure & 15 & 14.2 & 14.2 & 51.4 \\
\hline At risk & 51 & 48.6 & 48.6 & 100.0 \\
\hline Total & 105 & 100.0 & 100.0 & S.D =2.134 \\
\hline
\end{tabular}

Table 11: You face financial problems ?

\begin{tabular}{|c|c|c|c|c|}
\hline respondents & Frequency & percentage & Valid percent & Cumulative percent \\
\hline yes & 84 & 80 & 80 & 80 \\
\hline no & 21 & 20 & 20 & 100 \\
\hline total & 105 & 100 & 100 & S.D $=1.163$ \\
\hline
\end{tabular}

Table 12: Do you receive adequate material resources to perform your job?

\begin{tabular}{|c|c|c|c|c|}
\hline Responses & Frequency & Percent & Valid percent & Cumulative Percent \\
\hline Strongly Agree & 24 & 22.8 & 22.8 & 22.8 \\
\hline Agree & 28 & 26.7 & 26.7 & 49.5 \\
\hline Not Sure & 20 & 19.1 & 19.1 & 68.6 \\
\hline Disagree & 22 & 20.9 & 20.9 & 89.5 \\
\hline Strongly Disagree & 11 & 10.5 & 10.5 & 100.0 \\
\hline Total & 105 & 100.0 & 100.0 & \\
\hline
\end{tabular}


Table 13: What is the nature of your professional relationship with your colleagues?

\begin{tabular}{|c|c|c|c|c|}
\hline Responses & Frequency & Percent & Valid Percent & Cumulative \\
\hline Formal \& Satisfactory & 19 & 18.1 & 18.1 & 18.1 \\
\hline Informal \& Satisfactory & 20 & 19.1 & 19.1 & 37.2 \\
\hline Formal \&Unsatisfactory & 15 & 14.2 & 14.2 & 51.4 \\
\hline Informal \& Unsatisfactory & 51 & 48.6 & 48.6 & 100.0 \\
\hline Total & 105 & 100.0 & 100.0 & \\
\hline \multicolumn{4}{|c}{} \\
\hline
\end{tabular}

Table 14: If Un-satisfactory what are the reasons?

\begin{tabular}{|l|c|c|c|c|}
\hline Responses & Frequency & Percent & Valid Percent & Cumulative \\
\hline Attitude & 25 & 23.0 & 23.0 & 23.0 \\
\hline Work Load & 50 & 48.5 & 48.5 & 71.5 \\
\hline Working Environment & 30 & 28.5 & 28.5 & 100.0 \\
\hline Total & 105 & 100.0 & 100.0 & \\
\hline
\end{tabular}

Table 15: What is the nature of your professional relationship with doctors?

\begin{tabular}{|c|c|c|c|c|}
\hline Responses & Frequency & Percent & Valid Percent & Cumulative \\
\hline Percent \\
\hline Informal \& Satisfactory & 19 & 18.1 & 18.1 & 18.1 \\
\hline Formal \&Unsatisfactory & 20 & 19.1 & 19.1 & 37.2 \\
\hline Informal \& Unsatisfactory & 15 & 14.2 & 14.2 & 51.4 \\
\hline Total & 105 & 48.6 & 48.6 & 100.0 \\
\hline
\end{tabular}

Table 16: Are you subject to any kind harassment or unkind work at work place?

\begin{tabular}{|c|c|c|c|c|}
\hline Responses & Frequency & Percent & Valid percent & $\begin{array}{l}\text { Cumulative } \\
\text { percent }\end{array}$ \\
\hline Yes & 88 & 84.0 & 84.0 & 84.0 \\
\hline No & 17 & 16.0 & 16.0 & 100.0 \\
\hline Total & 105 & 100.0 & 100.0 & \\
\hline \multicolumn{4}{|c}{ S.D $=1.192$} \\
\hline
\end{tabular}

Table 17: During duty you faced psychological effects?

\begin{tabular}{|c|c|c|c|}
\hline RESPONSES & NUMBER OF RESPONDENTS & Valid percent & Cumulative \\
\hline Pes & 52 & 50 & 50 \\
\hline No & 16 & 15 & 65 \\
\hline Some time & 27 & 25 & 90 \\
\hline Not at all & 10 & 10 & 100 \\
\hline total & 105 & 100 & \\
\hline
\end{tabular}

Mean $=2.50$

S.D $=1.159$

Table 18: Type of Effects

\begin{tabular}{|c|c|c|c|}
\hline Response & Frequency & Percent & Cumulative Percent \\
\hline Anxiety & 20 & 19 & 19 \\
\hline Stress & 53 & 50 & 69 \\
\hline Mood Swing & 22 & 21 & 90 \\
\hline Other & 10 & 10 & 100 \\
\hline Total & 105 & 100 & \\
\hline
\end{tabular}


Table 19: What is the major cause hindrance in performing your job?

\begin{tabular}{|c|c|c|c|c|}
\hline Responses & Frequency & Percent & Valid Percent & Cumulative \\
\hline Percent \\
\hline Patients & 19 & 18.1 & 18.1 & 18.1 \\
\hline Attendants & 20 & 19.1 & 19.1 & 37.2 \\
\hline Colleagues & 15 & 14.2 & 14.2 & 51.4 \\
\hline Administration & 51 & 48.6 & 48.6 & 100.0 \\
\hline Total & 105 & 100.0 & 100.0 & \\
\hline \multicolumn{4}{|c|}{ S.D $=1.199$} \\
\end{tabular}

Nurses play a vital character in Providing health and medical service in any community. Due to improvements in field of medicine and new system of health care are developed the importance of nursing has increased manifold.

After completion of survey and analysis of data, it is necessary to discuss the key findings. One of the main purposes of this research study was to explore the effect of duties and current working conditions of the nurses in of Bahawal Victoria Hospital. All nurses working in of Bahawal Victoria Hospital. are females and vast majority of them are between the age brackets of 20-30 Years. Majority of nursing staff having professional experience of less than 6 year. This shows that nurses in of Bahawal Victoria Hospital are mostly young with moderate level of work experience, senior nurses or highly experienced are lacking in numbers. The reasons for such classification is may be due to nature of the job as it is highly laborious and tiring job.

On the other hand this may be seen as lack shortage of experience staff which is obviously more competent and can work under pressure and specialized situations with maximum efficiency. Majority of nurses are having graduation as there maximum educations, even nurses with experience of more than 15 years have graduation as at their highest qualification.

\section{Conclusion}

Government must provide the accommodation facilities like staff colony for the nurses. The hospital administration should reduce the working hours of nurses to make some sort of relive Born their workload' There must be sufficient paid leaves in a year for the nurses. A proper service structure should be developed so the promotions and demotions should be done in accordance with some Preset rules and standards.

There should be cooperation between the nursing staff for the better care of the patients.. The hospital administration should behave equally with all the nursing staff. Hospital administration should provide medicine stock within the ward where nurses are performing their duties. Ward masters should be appointed for Ward management and nurses should be relived of this extra burden of managing the wards along with performing there clinical duties.

Nurses must participate in sports and extracurricular activities after a regular interval to get them strained out from stress, burn out and worries. They must raise their voice for the protection of their rights with regard to their job performance. Nurses must be appreciate and acknowledge through awards and appreciation certificates by the administration.

\section{Recommendations}

Quick and strict action should be taken against those who try to harass the nursing staff.

$>$ Medical officers should act cooperatively with the nursing staff and adopt polite and humble behavior.

$>$ Job security of the nurses must be made ensure by the hospital administration

$>$ People should be made aware about the importance and Prestigious-ness of nursing as a profession in health care setting. The attendants should maintain healthy cooperation with the nurses for the early recovery of their patients. People will have to change their conservative mind set about nursing. Nurses should be appreciated for their efforts which they put into deliver the best possible care to the sick.

$>$ Government should develop a detailed policy regarding roles and responsibilities and show proper description of their duty timings.

$>$ Government mentioned the proper description of their incentives.

\section{References}

[1.] Aiken LH, C. S. (2001). Nurses' reports on hospital care in five countries. Health Affairs.

[2.] Alderson, M. (2008). Work Structure in the Chronic Care Setting: Possible Consequences for Nurses ${ }^{\text {ee }}$ Mental Health. Canadian Journal of Nursing Research, 160-78.

[3.] AM., W. (1998). The delivery of nursing care: a grounded theory study of nurses ${ }^{\text {ee }}$ perspective. Journal of Advanced Nursing, 808-16.

[4.] Baly, M. (1997).Folrence Nightingale and the nursing legacy (2nd ed.). London: Whurr.

[5.] Berland A, N. G. (2008). Patient safety and job-related stress: A focus group study. Intensive and Critical Care Nursing, 90-97. 
[6.] Billeter- Koponen S, F. L. (2005). Long-term stress, burnout and patient-nurse relations: qualitative interview study about nursese experiences. Scandinavian Journal of Caring Science, 20-27.

[7.] Cheng Y, K. I. (2008). Association between psychosocial work characteristics and health functioning in American woman: prospective study. British Medical Journal, 1432: 6-320.

[8.] Cohen S, J.-D. D. (2007).Psychological stress and disease. The Journal of the American Medical Association, 298.

[9.] Correa, A. R. (2009, August 16). "A Closer Look at Nursing Profession". http://www.medvarsity.com/Articles/Reena.html.

[10.] Dolan, J. (1968). History of nursing (12th ed.). Philadelphia: W.B. Saunders.

[11.] Effionm D, E. J. (2007). A comparative study of occupational stress among Nurses and non-Nurses in the University Teaching Hospital Calabar, Nigeria.West African Journal of Nursing. , 101-4. 